\title{
England hikes educational requirements for nurses
}

Published at www.cmaj.ca on Dec. 21, 2009

$\mathrm{T}$ he minimum entry requirement for nurses in England will be raised to a four-year degree by 2013 in a bid to improve patient care and elevate the status of nurses in the United Kingdom.

The current entry requirement - a two- or three-year diploma - will be elevated to four years of courses that meet standards to be set by the Nursing and Midwifery Council, the current professional regulator for nurses, over the next two years. A review by the council had concluded that higher educational standards would enable newly qualified nurses to be "more assertive, more questioning and take more responsibility."

The Royal College of Nursing described the move as "an important and historic development." Higher education standards will prepare nurses for the "increasingly advanced levels of practice and clinical knowledge" now demanded of nurses, stated Dr. Peter Carter, the college's chief executive officer and general secretary in a press release (www.rcn.org.uk/news events/news/article/uk/rcn_welcomes _all_graduate_nursing).

But concerns have been raised by unions and patients who fear the new requirements will worsen existing nursing shortages and produce elitist nurses who would feel the menial work of nursing — such as washing, feeding or helping patients to the bathroom - as being below them.

As well, says Gail Adams, the head of nursing for UNISON, England's largest public sector health union, closing diploma programs will exclude willing recruits at a time when England's National Health Service needs them the most. "The diploma system had enabled students from varied backgrounds to become nurses," she wrote in an email.

Adams earlier stated in a press release that the diploma route is also

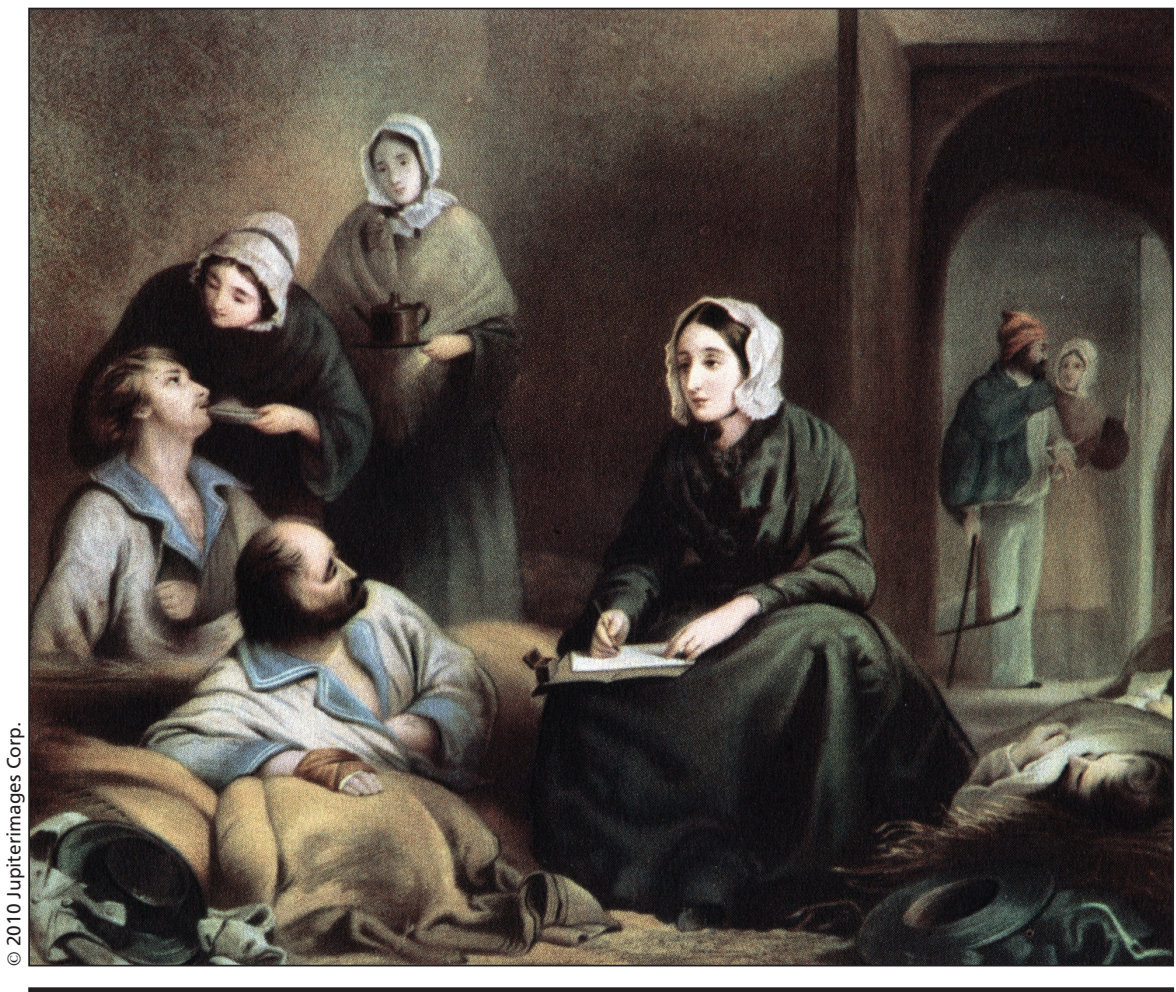

England will make nursing an all-graduate profession by 2013 in an attempt to better prepare students for the challenges of modern health care, but health unions and patients fear degree nurses will relegate compassionate care to the distant past.

more attractive to mature workers who have the experience but not necessarily the academic qualifications to go for a degree (www.unison.org.uk/asppress pack/pressrelease_view.asp?id=1099).

"The emphasis should be on the competence of the nurse, not on unfounded notions about academic ability," she stated.

Ann Moses, chair of UNISON's Nursing Sector, said in the same release that "many nurses fear that the proposed changes would lead to a reduction in the number of registered nurses" and that the role of those would become "supervisory" in nature.

The Royal College doubted that changes would restrict entry into the nursing profession or result in shortages, although, according to figures from the Higher Education Statistical Agency, $10.3 \%$ of university nursing students drop out, compared to $9 \%$ of other students. Nursing degree students in England also have less access to financial aid than those training in diploma programs. Diploma students are eligible for annual grants of $£ 7000$, while university students typically rely on means-tested loans.

Despite existing staffing shortages in areas such as midwifery, emergency and neonatal care, James Parsons, head of the health care division of the recruitment agency Arrows Group, says the additional training will be welcome. "I'm definitely in favour of this measure, in terms of offering more career development to nurses."

The Patients Association, meanwhile, worried that shifting training from the bedside to the classroom will fail to teach the basics of nursing care, specifically, "dignity, compassion and, above all, safety." Moreover, the 
change may lead to nurses neglecting the needs of their patients in pursuit of "the personal prizes of nurse specialisms," the association stated in a press release (www.patients-association .org.uk/News/315).

In a recent report, Patients not Numbers, People not Statistics, the association described cases of already inadequate patient care resulting from nurses neglecting the fundamentals of feeding, bathing and toileting (www.patients -association.org.uk/Research-Publications 1297). The study indicated that patients were being "left in soiled bedclothes, being given inadequate food and drink, having repeated falls, suffering from late diagnosis, cancelled operations, bungled referrals and misplaced notes," said Katherine Murphy, the association's director, in a press release.

The decision to switch nursing to an all-degree profession in England resulted from a consultation and review of preregistration training conducted by the Nursing and Midwifery Council, and follows the lead set by Wales, which began the transition to all-graduate training in 2004. - Mary Helen Spooner, London, England, and Lauren Vogel, Ottawa, Ont.

DOI:10.1503/cmaj.109-3142 